Research Article

\title{
Biomonitoring of Workers Exposed to Volatile Organic Compounds Associated with Different Occupations by Headspace GC-FID
}

\author{
Ghazala Yaqub (D), Almas Hamid, Nikhat Khan, Sunaina Ishfaq, Asha Banzir, \\ and Tayyaba Javed
}

Department of Environmental Sciences, Kinnaird College for Women, Lahore 54000, Pakistan

Correspondence should be addressed to Ghazala Yaqub; ghazala_yaqub@yahoo.com

Received 10 January 2020; Accepted 23 April 2020; Published 8 May 2020

Guest Editor: Yifeng Zhang

Copyright (c) 2020 Ghazala Yaqub et al. This is an open access article distributed under the Creative Commons Attribution License, which permits unrestricted use, distribution, and reproduction in any medium, provided the original work is properly cited.

\begin{abstract}
The present study has been undertaken to analyze the total accumulated burden of volatile organic compounds (VOCs) in blood of occupationally exposed workers. The headspace technique combined with gas chromatography with flame ionization detector was used for the quantitative analysis of the different volatile organic compounds (isopropyl alcohol, phenol, benzene, dichloromethane, ethanol, ethyl acetate, and toluene) in 80 blood samples from the workers belonging to different occupations i.e., shoe polish workers, thinner handlers, paint workers, furniture polish workers, petrol station attendants, textile dyeing workers, printing press workers, and dry port workers as biomonitoring is one of the most promising methods for analyzing the individual burden of VOCs. Another purpose of this study was to investigate the correlation between detected concentrations of VOCs and associated health issues reported by the workers of these professions. Results of the study revealed the presence of different VOCs in blood samples of approximately 70 workers out of 80 , and statistical analysis proved a strong relationship between the reported work experience, working hours, and diseases and the detected concentrations of respective volatile organic compounds.
\end{abstract}

\section{Introduction}

Organic solvents, isopropyl alcohol, phenol, benzene, dichloromethane, ethanol, ethyl acetate, and toluene, are present in a wide range of commercially available products and have been widely used in different workplaces and industrial sectors (e.g., in manufacturing of paints, adhesives, thinners, glues, plastic, pitch, bitumen, and some pharmaceutical products; in shoe polish industries; in printing presses; and in petroleum industries) and as intermediate in the formation of other chemical substances according to their requirements. They are direct or indirect source of volatile organic compounds (VOCs) at workplaces.

Solvents use in different workplaces has rapidly increased in recent era. Individuals living or working in such conditions are commonly exposed to pollutants released from solvents. Most of these organic solvents are considered as environmental contaminants because of their high volatility and hazardous nature, even when they are present in low concentrations.
VOCs are also considered as environmental contaminants because they persist in the air [1]. In recent years VOCs in the atmosphere has gained much attention due to their direct and indirect effects. Many VOCs are very toxic and others are supposed to be carcinogenic. The direct effects of these toxic compounds are their potential to cause serious health effects [2]. On the other hand, indirect effects of VOCs are related to their typical reactions in troposphere. Different species of VOCs behave differently while taking part in the formation of tropospheric ozone [3]. VOCs can enter our body through several routes. Inhalation is usually the most common and known route of entry of VOCs into our body, but they may enter the body also by absorption through skin which further leads to irritation of skin, eyes, nose, and throat. The common characteristic of all VOCs is that "they are lipid-soluble." The key target of all VOCs is brain and causes dizziness, loss of concentration, headache, and memory loss after their accumulation in blood and urine. Health effects due to occupational exposure of VOCs include kidney and liver damage and effects on central nervous system 
(CNS) including memory loss, balance and gait disturbances, diminished cognition, and hand-eye and foot-eye coordination. Common symptoms are depressions, irritability, mood disorders, and fatigue. VOCs can also trigger exacerbation of asthma in very severe cases [2].

The extent to which and the complete details on how VOCs affect human health are still unknown. Several studies have observed that the VOCs exposure is more in occupational settings compared to environmental settings. Biomonitoring is a most promising method to analyze individual burden of these contaminants. It provides useful information on toxic build-up of chemicals in body mainly in fatty tissues [4]. Biomonitoring also allowed the determination of the individual health risk and the measurement of the target analytes concentration in the environment $[5,6]$. Volatile organic compounds like benzene, phenols, alcohols, and toluene have been a great concern, as they pose serious health concern, when inhaled [4]. Solvent inhalation is usually occupational and not intentional, requiring serious preventive control of solvent use in industrial or commercial sites. Several researches works on the monitoring of exposure to such compounds [7-9], and their effects on human health have been reported [10]. One way to measure the human contamination with volatile organic compounds is to test urine or blood samples [11]. Different methods have been developed for the determination of solvents and VOCs in blood and/or urine. However, most of the promising and successful studies reported the biomonitoring of such compounds in urine and blood samples by gas chromatography or GC-MS. There are many techniques which can be used to analyze VOCs in blood. These techniques are gas chromatography-mass spectrometer (GC-MS), headspace gas chromatography along with mass spectrometer (HS-GC-MS), and gas chromatography with flame ionization detector (GC-FID).

Due to the severity of VOCs effects on environment and human health, the present study was designed to analyze total burden of VOCs in exposed workers blood. In future, this research may be helpful for suggesting major priorities in the light of its outcomes, in order to minimize occupational related health issues and to ensure complete safety of worker at their workplaces. This study thus focused on the headspace technique combined with GC-FID for the qualitative and quantitative determination of VOCs in blood of occupationally exposed workers and for the investigation of the correlation between the detected concentration of VOCs and associated health issues reported by the workers of these occupations [12].

\section{Study Population}

For the purpose of biomonitoring of VOCs, workers belonging to following industrial/occupational sectors have voluntarily participated in the study.

(i) Shoe polish workers

(ii) Thinner handlers

(iii) Paint workers

(iv) Furniture polish workers

(v) Petrol station attendants (vi) Textile dyeing and printing press workers

(vii) Petroleum products handlers at dry port

The main components involved in the manufacturing of paint are pigments (including titanium dioxide) solvents, resins, and additives.

\section{Materials and Methods}

The current study was carried out to determine the concentrations of VOC level in blood of occupationally exposed workers by gas chromatography with flame ionization detector. Analytical grade chemicals, i.e., methanol, isopropyl alcohol, phenol, benzene, dichloromethane, ethanol, ethyl acetate, and sodium chloride, were used for present research.

3.1. Data Collection. Secondary data were gathered to develop questionnaire and methodology and to review literature. For primary data collection, series of meetings with each workplace manager were planned and necessary information was gathered. Walkthrough survey was conducted in order to check the type of solvents being used by industries/workplaces and to analyze the environmental/ working conditions of workers. Interviews were held with workers of the associated professions, and a questionnaire was filled to get information regarding their work experience, working hours, smoking habits, exposure time, and diseases they suffer like headache, fatigue, skin problems/ allergies, irritation to eyes, irritation to nose/breathing problem/nausea, irritation to throat, weakness, dizziness, diabetes, migraine, cancer, obesity, and others if any.

3.2. Consent Form. Ethical guidelines and protocols were completely followed/adopted during the whole research. According to the international ethical guidelines for biomedical research, consent should be obtained from those workers who are voluntarily participating in the research [13]. In the present research, participation of all workers was voluntary. Their blood samples used in the present research were taken after 8-hour work shift and were stored with private code numbers. After the workers' verbal commitment to participate in the present research, they were asked to sign a consent form.

3.3. Selection of Exposed Workers. Exposed workers were selected on the basis of primary data. The workers fall in the age range of 18-45 years and have the average working experience of 3-12 years. Workers of all the selected industries work averagely for 8-10 hours per day. All the workers when asked said that they have the habit of smoking. Although they were being provided with personal protective equipment (PPE), i.e., gloves and face masks, they were not using them, because according to them wearing the PPE decreases their work efficiency. Table 1 shows workplaces/industrial sectors and the number of selected workers. 
TABLE 1: Industries and their selected workers.

\begin{tabular}{|c|c|c|c|}
\hline Sr. no. & Industries/workplaces & Workers' duty section/department & Selected no. of workers \\
\hline \multirow{2}{*}{1} & \multirow{2}{*}{ Textile industry } & Dyeing & 9 \\
\hline & & Printing & 10 \\
\hline \multirow{2}{*}{2} & \multirow{2}{*}{ Electrical industry } & Painting & 5 \\
\hline & & Thinner handling & 2 \\
\hline 2 & Petrol station & Petrol filling & 7 \\
\hline 3 & Furniture workshops & Furniture polish & 5 \\
\hline \multirow[t]{2}{*}{4} & Dry port workers & & 10 \\
\hline & Small-sized printing press & & 10 \\
\hline \multirow[t]{2}{*}{5} & Medium-sized printing press & Printing & 10 \\
\hline & Large-sized printing press & & 10 \\
\hline \multirow[t]{2}{*}{6} & Others & Shoe polish & 2 \\
\hline & & & 2 \\
\hline \multirow[t]{2}{*}{7} & \multirow{2}{*}{\multicolumn{2}{|c|}{ Control (general population) }} & Total workers $=80$ \\
\hline & & & Control samples $=2$ \\
\hline
\end{tabular}

3.4. Selection of VOCs for Blood Analysis. VOCs such as isopropyl alcohol, phenol, benzene, dichloromethane, ethanol, and ethyl acetate were selected to be analyzed in blood of workers based on literature and information gathered during primary data collection.

3.5. Blood Collection Method. For the collection of blood samples from workers, a trained paramedical staff member was hired. Samples were collected after 15-20 minutes of 8hour work shift. For VOCs analysis in blood, gray top Vacutainer tubes of $5 \mathrm{~mL}$ were selected depending on the need of samples. These Vacutainer tubes already contained sodium fluoride and potassium oxalate as preservative and anticoagulant. The blood samples of workers were obtained by venipuncture (using BD $5 \mathrm{ml}$ syringe) as described by Cardinali et al. and Ashley et al. [14, 15]. After blood collection, the vial was shaken well 2-3 times to prevent blood from clotting. Blood samples were then immediately placed in a container of ice cubes. Finally the samples were transferred to laboratory and were stored at $4^{\circ} \mathrm{C}$. The collected blood samples were analyzed within the same day.

3.6. Preparation of Blood Samples and Standards. After collection, blood samples were quickly transferred to laboratory and were analyzed by headspace method for gas chromatography. $2 \mathrm{ml}$ of blood sample was transferred from Vacutainer tube to $16 \mathrm{ml}$ headspace vial which already contains $1 \mathrm{ml}$ of sodium chloride, and it was sealed immediately with a silicone/PTFE septum. Blood sample was gently stirred for $5-10 \mathrm{~min}$ and was then incubated at $60^{\circ} \mathrm{C}$ for about $35-40 \mathrm{~min}$. After partial pressure has been achieved, $0.5 \mathrm{ml}$ of headspace air was injected into the gas chromatograph for further analysis. This technique was previously used for identification of variety of solvents and was also successfully employed in our laboratory. A discard box was prepared to put all the used syringes, Vacutainer tubes, microfilters, gloves, vials, and other hazardous waste. Every time after sample preparation, the discard box was immediately sent to the nearest hospital waste bin with great care. For preparation of standards of selected volatile organic compounds, method quoted by EI-Haj et al. was followed with few modifications according to laboratory conditions [16]. The chromatographic coelution of selected VOCs was also evaluated by direct injection of these compounds into the GC [17].

3.7. Analytical Analysis. Gas chromatography with flame ionization detector (GC-FID) was used for qualitative and quantitative determination of VOCs in blood samples. GC was equipped with both split and splitless capillary injectors. Temperature of both detector and injection was kept at $200^{\circ} \mathrm{C}$ while column temperature was programmed between 50 and $100^{\circ} \mathrm{C}$. N2 flow and $\mathrm{H} 2$ flow were both kept at $40 \mu \mathrm{L} / \mathrm{min}$ while air flow was $400 \mu \mathrm{L} / \mathrm{min}$. Total run time was $15 \mathrm{~min}$.

3.8. Method Development and Quality Control. A rapid and sensitive gas chromatographic method was developed and validated to determine different VOCs in blood samples. For method development, studies were performed on each GC parameter, and for optimization, one parameter was changed at one time while all others were kept constant. In order to ensure method precision, each sample was analyzed in triplicate to record the variation (if any), and mean value was considered. Calibration experiments were tested for linearity, accuracy, and precision. Limit of detection $(3: 1)$ and limit of quantification $(10: 1)$ were calculated as signalnoise ratio.

3.9. Qualitative and Quantitative Analysis. Qualitative analysis on the basis of peak height and retention time was done to determine the presence of different VOCs in the prepared blood samples.

Quantitative analysis of results was done by calculating response factor and relative response factor (RRF) by formulas given below.

3.10. Response Factors. From results of analytes, peak area and concentration were taken to calculate response factor. Equations (1) and (2) were used to calculate response factor of samples and standards [18]: 


$$
\begin{aligned}
& \text { responce factor }=\frac{\text { peak area of standard }}{\text { concentration }}, \\
& \text { response factors }=\frac{\text { peak area of sample }}{\text { concentration }} .
\end{aligned}
$$

The calculated response factors of standard (1) and sample (2) were then used to calculate relative response factor (RRF) between two analytes. The following equation was used to calculate relative response factor [17]:

$$
\text { relative response factor }(\mathrm{RRF})=\frac{\text { response factor } \mathrm{B}}{\text { response factor } \mathrm{A}} \text {. }
$$

Relative response factor was further used in order to calculate the unknown concentration of analyte (VOC selected):

$$
\begin{aligned}
\text { concentration of analyte }= & \frac{\text { peak area of } A}{\text { peak area of } B} \times \frac{1}{\mathrm{RRF}} \\
& \times \text { concentration of standard. }
\end{aligned}
$$

3.11. Statistical Analysis. Statistical analysis was done with Microsoft Excel version 4.0 on personal computer. Primary data were collected from the workers of all occupations, and the questions asked were related to work experience, working hour, workplace conditions (status of work), and diseases such as headache, fatigue, skin problems/allergies, irritation to eyes, irritation to nose/breathing problem/ nausea, irritation to throat, weakness, dizziness, diabetes, migraine, cancer, and obesity; all these data were statistically analyzed with the detected concentrations of different VOCs. Statistical test, i.e., "phi coefficient," was selected for analysis as phi is interpretable as a nonparametric correlation coefficient and means just the same thing as the Pearson $r$ in terms of the strength and direction of the relationship between two variables.

\section{Results and Discussion}

Occupational exposure to solvents may often lead to serious illnesses and injuries through absorption of irritants via skin and/or inhalation of toxic vapors. The risk may become worse while working in confined areas. Several studies have reported various adverse effects of solvent intoxication such as neuropathological effects, nephrotoxic effects, hepatotoxic effects, and cognitive impairment $[19,20]$.

The purpose of the present study was to analyze total burden of VOCs in blood of occupationally exposed workers by using GC-FID. Total collected blood samples of workers were 80 , i.e., two shoe polish workers, two thinner handlers, five paint workers, five furniture polish workers, seven petrol station attendants, nine textile dyeing workers, ten textile printing workers, ten dry port workers, and thirty printing press workers. All of the participating workers were male. Two control samples were also taken from the general population people (who do not have any previous or current record of occupational exposure to solvents) (Table 2).

A detailed questionnaire was designed to obtain information of participants regarding age, BMI, work experience, exposure period, health issues, and present working environments (as mentioned earlier in Section 3).

Blood samples were analyzed for presence of VOCs both qualitatively and quantitatively. All samples were run in triplicate for quality assurance, and mean value was considered. Analysis showed the presence of isopropyl alcohol in almost all blood samples which were collected from shoe polish workers, paint workers, furniture polish workers, one thinner handler, and three printing press workers. All these workers were apparently underweight and normal. The detected concentration of isopropyl alcohol in shoe polish workers was $15.2 \mathrm{ppm}$ and $20.3 \mathrm{ppm}$. The concentration of isopropyl alcohol detected in thinner handlers was $30.0 \mathrm{ppm}$. In paint workers, it was detected in concentration of $22.54 \mathrm{ppm}$, $35.9 \mathrm{ppm}, 351.38 \mathrm{ppm}, 23.6 \mathrm{ppm}$, and $33.85 \mathrm{ppm}$, respectively. In blood of furniture polish workers isopropyl alcohol was present in concentration of $21.0 \mathrm{ppm}$, 25.9 ppm, 22.9 ppm, $226.75 \mathrm{ppm}$, and $18.49 \mathrm{ppm}$, while its determined concentration in blood of printing press workers was $28.44 \mathrm{ppm}, 80.64 \mathrm{ppm}$, and $82.64 \mathrm{ppm}$, respectively. The samples taken from petrol station attendants, textile dyeing workers, textile printing workers, and dry port workers did not show its presence in their blood. During primary data collection, the health effects reported by affected workers were irritation to skin, eyes, throat, headache, fatigue, and sometimes weakness during duty. Furthermore, furniture and shoe polish workers and some textile dyeing workers had also complained about nose irritation. Their response is also supported by hazardous fact sheet prepared by New Jersey Department of Health which highlighted the fact that contact to isopropyl alcohol can cause irritation to skin and eyes, while inhaling it can cause nose and throat irritation. Overexposure can cause unconsciousness, confusion, headache, and loss of coordination [21]. Among all samples, phenol was detected and quantified in blood samples of one petrol station attendant in concentration of $2.39 \mathrm{ppm}$, five textile dyeing workers (3.52 ppm, 3.18 ppm, $3.02 \mathrm{ppm}, 2.69 \mathrm{ppm}$, and $3.13 \mathrm{ppm}$ ), and five printing press workers $(4.82 \mathrm{ppm}, 3.24 \mathrm{ppm}$, $3.2 \mathrm{ppm}, 16.36 \mathrm{ppm}$, and 16.00). Phenol was not detected in any other sample. Workers (with phenols detected in blood) also reported problems like irritation to skin, eye, and throat; headache; fatigue; and sometimes weakness which is also supported by hazardous fact sheet prepared by New Jersey Department of Health indicating that exposure to phenol can cause throat, skin, and eye irritation and sometimes lead to skin burns and eye damage. Its high exposure may reduce the blood ability to transport oxygen, causing fatigue, headache, dizziness, and blue color to lips and skin [22].

Benzene, a solvent for paints, inks, and plastics, is used in manufacturing of dyes, rubbers, drugs, lubricants, pesticides, and detergents and was found in one blood sample of a 
TABLE 2: Quantitative analysis of VOCs in blood samples.

\begin{tabular}{|c|c|c|c|c|c|c|c|c|c|}
\hline Sr. no. & Participants & $\begin{array}{l}\text { Sample } \\
\text { code }\end{array}$ & $\begin{array}{c}\text { Isopropyl } \\
\text { alcohol (ppm) }\end{array}$ & $\begin{array}{l}\text { Phenol } \\
\text { (ppm) }\end{array}$ & $\begin{array}{l}\text { Benzene } \\
\text { (ppm) }\end{array}$ & $\begin{array}{l}\text { Dichloromethane } \\
\text { (ppm) }\end{array}$ & $\begin{array}{l}\text { Ethanol } \\
\text { (ppm) }\end{array}$ & $\begin{array}{c}\text { Ethyl } \\
\text { acetate } \\
\text { (ppm) }\end{array}$ & $\begin{array}{l}\text { Toluene } \\
\text { (ppm) }\end{array}$ \\
\hline \multirow{2}{*}{1} & \multirow{2}{*}{$\begin{array}{c}\text { Shoe polish } \\
\text { workers }\end{array}$} & 68635 & 15.2 & 0 & 0 & 0 & 0 & 0 & 0 \\
\hline & & 68183 & 20.3 & 0 & 0 & 0 & 0 & 0 & 0 \\
\hline \multirow{2}{*}{2} & \multirow{2}{*}{$\begin{array}{c}\text { Thinner } \\
\text { handlers }\end{array}$} & 68189 & 30.0 & 0 & 0 & 0 & 0 & 0 & 0 \\
\hline & & 68458 & 0 & 0 & 0 & 0 & 0 & 17.51 & 0 \\
\hline \multirow{5}{*}{3} & \multirow{5}{*}{ Paint workers } & 671 & 22.54 & 0 & 0 & 0 & 0 & 35.95 & 0 \\
\hline & & 67425 & 35.9 & 0 & 0 & 0 & 0 & 373.70 & 0 \\
\hline & & 68503 & 351.83 & 0 & 0 & 0 & 0 & 25.12 & 0 \\
\hline & & 68202 & 23.6 & 0 & 0 & 0 & 0 & 0 & 0 \\
\hline & & 67435 & 33.85 & 0 & 0 & 0 & 0 & 31.84 & 0 \\
\hline \multirow{5}{*}{4} & \multirow{5}{*}{$\begin{array}{l}\text { Furniture polish } \\
\text { workers }\end{array}$} & 68205 & 21.0 & 0 & 0 & 0 & 0 & 0 & 0 \\
\hline & & 68453 & 25.9 & 0 & 0 & 0 & 0 & 0 & 0 \\
\hline & & 68249 & 22.9 & 0 & 0 & 0 & 0 & 0 & 0 \\
\hline & & 68147 & 226.75 & 0 & 0 & 0 & 0 & 0 & 0 \\
\hline & & 68203 & 18.49 & 0 & 0 & 0 & 0 & 0 & 0 \\
\hline \multirow{2}{*}{5} & \multirow{2}{*}{$\begin{array}{c}\text { Petrol station } \\
\text { attendants }\end{array}$} & 69189 & 0 & 2.39 & 0 & 0 & 0 & 0 & 0 \\
\hline & & 68259 & 0 & 0 & 0 & 0 & 9.73 & 0 & 0 \\
\hline \multirow{9}{*}{6} & \multirow{9}{*}{$\begin{array}{l}\text { Textile dyeing } \\
\text { workers }\end{array}$} & 215394 & 0 & 3.52 & 0 & 0 & 0 & 0 & 0 \\
\hline & & 215477 & 0 & 3.18 & 0 & 0 & 0 & 0 & 0 \\
\hline & & 68235 & 0 & 0 & 0 & 0 & 1.31 & 0 & 0 \\
\hline & & 683615 & 0 & 0 & 0 & 6.49 & 0 & 0 & 0 \\
\hline & & 1046747 & 0 & 3.02 & 0 & 0 & 0 & 0 & 0 \\
\hline & & 68361 & 0 & 0 & 81.62 & 6.40 & 0 & 0 & 0 \\
\hline & & 1046456 & 0 & 2.69 & 0 & 0 & 0 & 0 & 0 \\
\hline & & 68387 & 0 & 0 & 0 & 5.05 & 0 & 0 & 0 \\
\hline & & 215654 & 0 & 3.13 & 0 & 0 & 0 & 0 & 0 \\
\hline \multirow{10}{*}{7} & \multirow{10}{*}{$\begin{array}{l}\text { Textile printing } \\
\text { workers }\end{array}$} & 1022195 & 0 & 0 & 0 & 5.01 & 0 & 0 & 0 \\
\hline & & 215636 & 0 & 0 & 0 & 7.85 & 0 & 0 & 0 \\
\hline & & 215377 & 0 & 0 & 0 & 6.64 & 0 & 0 & 0 \\
\hline & & 215478 & 0 & 0 & 0 & 6.64 & 0 & 0 & 0 \\
\hline & & 1047332 & 0 & 0 & 0 & 5.34 & 0 & 0 & 0 \\
\hline & & 215491 & 0 & 0 & 0 & 6.86 & 0 & 0 & 0 \\
\hline & & 215330 & 0 & 0 & 0 & 5.48 & 0 & 0 & 0 \\
\hline & & 1022687 & 0 & 0 & 0 & 5.67 & 0 & 0 & 0 \\
\hline & & 10464567 & 0 & 0 & 0 & 4.53 & 0 & 0 & 0 \\
\hline & & 68234 & 0 & 0 & 0 & 7.85 & 0 & 0 & 0 \\
\hline \multirow{10}{*}{6} & \multirow{10}{*}{$\begin{array}{l}\text { Dry port } \\
\text { workers }\end{array}$} & 00215357 & 0 & 0 & 199.89 & 0 & 0 & 0 & 0 \\
\hline & & 00214411 & 0 & 0 & 0.776 & 0 & 95.89 & 0 & 0 \\
\hline & & 00216744 & 0 & 0 & 0.06 & 0 & 49.72 & 0 & 0 \\
\hline & & 00215616 & 0 & 0 & 0.97 & 0 & 141.63 & 0 & 0 \\
\hline & & 00213477 & 0 & 0 & 0 & 0 & 88.80 & 0 & 0.000001 \\
\hline & & 00217018 & 0 & 0 & 0 & 0 & 24.74 & 0.016 & 0.006 \\
\hline & & 00216755 & 0 & 0 & 0 & 0 & 88.80 & 0.0012 & 0 \\
\hline & & 00215616 & 0 & 0 & 0 & 0 & 0 & 0.01 & 0 \\
\hline & & 00215590 & 0 & 0 & 0 & 0 & 110.89 & 1.06 & 0 \\
\hline & & 00216676 & 0 & 0 & 0 & 0 & 133.76 & 0 & 0 \\
\hline \multirow{6}{*}{7} & \multirow{6}{*}{$\begin{array}{l}\text { Small-sized } \\
\text { printing press }\end{array}$} & 68360 & 0 & 0 & 0 & 0 & 15.61 & 0 & 0 \\
\hline & & 68303 & 28.44 & 0 & 0 & 0 & 0 & 0 & 0 \\
\hline & & 68392 & 0 & 4.82 & 0 & 0 & 0 & 0 & 0 \\
\hline & & 68366 & 0 & 0 & 0 & 10.94 & 0 & 0 & 0 \\
\hline & & 68213 & 0 & 3.24 & 0 & 0 & 0 & 0 & 0 \\
\hline & & 68241 & 0 & 0 & 5.16 & 0.41 & 0 & 0 & 0 \\
\hline
\end{tabular}


TABLE 2: Continued.

\begin{tabular}{|c|c|c|c|c|c|c|c|c|c|}
\hline Sr. no. & Participants & $\begin{array}{l}\text { Sample } \\
\text { code }\end{array}$ & $\begin{array}{c}\text { Isopropyl } \\
\text { alcohol (ppm) }\end{array}$ & $\begin{array}{l}\text { Phenol } \\
\text { (ppm) }\end{array}$ & $\begin{array}{l}\text { Benzene } \\
(\text { ppm })\end{array}$ & $\begin{array}{l}\text { Dichloromethane } \\
\text { (ppm) }\end{array}$ & $\begin{array}{l}\text { Ethanol } \\
(\mathrm{ppm})\end{array}$ & $\begin{array}{l}\text { Ethyl } \\
\text { acetate } \\
(\mathrm{ppm})\end{array}$ & $\begin{array}{c}\text { Toluene } \\
\text { (ppm) }\end{array}$ \\
\hline \multirow{9}{*}{8} & \multirow{9}{*}{$\begin{array}{l}\text { Medium-sized } \\
\text { printing press }\end{array}$} & E31986 & 0 & 0 & 0 & 6.6 & 0 & 0 & 0 \\
\hline & & E47334 & 0 & 0 & 0 & 319.28 & 0 & 0 & 0 \\
\hline & & E68353 & 0 & 3.2 & 0 & 0 & 0 & 0 & 0 \\
\hline & & E68387 & 0 & 0 & 0 & 7.24 & 0 & 0 & 0 \\
\hline & & E68352 & 0 & 0 & 0 & 0 & 16.7 & 0 & 0 \\
\hline & & E35231 & 0 & 0 & 0 & 8.07 & 0 & 0 & 0 \\
\hline & & E46452 & 0 & 0 & 0 & 7.42 & 0 & 0 & 0 \\
\hline & & E31987 & 0 & 0 & 0 & 6.6 & 0 & 0 & 0 \\
\hline & & E31999 & 0 & 0 & 0 & 15.61 & 0 & 0 & 0 \\
\hline \multirow{4}{*}{9} & \multirow{4}{*}{$\begin{array}{l}\text { Large-sized } \\
\text { printing press }\end{array}$} & 215328 & 0 & 0 & 0 & 5.85 & 0 & 0 & 0 \\
\hline & & 215335 & 0 & 0 & 0 & 6.81 & 0 & 0 & 0 \\
\hline & & 215455 & 80.64 & 16.36 & 0 & 0 & 0 & 0 & 0 \\
\hline & & 215656 & 82.64 & 16.00 & 0 & 0 & 0 & 0 & 0 \\
\hline
\end{tabular}

textile dyeing worker in concentration of $81.62 \mathrm{ppm}$, one blood sample of a textile printing worker (5.16 ppm), four blood samples of dry port workers (199.89 ppm, $0.776 \mathrm{ppm}$, $0.06 \mathrm{ppm}$, and $0.97 \mathrm{ppm}$ ), and one sample of a printing press worker (5.16). During survey the prominent reported health effects of the exposed worker were again irritation to skin, eye, and throat; headache; weakness; and fatigue during their working hours which are also supported by literature; according to a report prepared by Agency for Toxic Substances and Disease Registry (ATSDR), very small exposure ( 5 to 10 minutes) to a very high level of benzene in air $(10,000$ to $20,000 \mathrm{ppm}$ ) can result in death. Lower levels (700 to $3,000 \mathrm{ppm}$ ) can cause headache, unconsciousness, dizziness, drowsiness, and confusion [23]. It is also a moderate skin and eye irritant [24]. Dichloromethane (DCM), also known as methylene chloride, is widely used as a solvent in adhesives, paint strippers and removers, textile printing, and printing presses. In the current study, DCM was found in only three blood samples of textile dyeing workers (6.49 ppm, $5.05 \mathrm{ppm}$, and $6.40 \mathrm{ppm})$, all blood samples collected from textile printing workers $(5.01 \mathrm{ppm}, 7.85 \mathrm{ppm}$, $6.64 \mathrm{ppm}, \quad 6.64 \mathrm{ppm}, \quad 5.34 \mathrm{ppm}, \quad 6.86 \mathrm{ppm}, \quad 5.48 \mathrm{ppm}$, $5.67 \mathrm{ppm}, 4.53 \mathrm{ppm}$, and $7.85 \mathrm{ppm})$, and eleven blood samples of printing press workers $(10.94 \mathrm{ppm}, 0.41 \mathrm{ppm}$, $6.6 \mathrm{ppm}, \quad 319.28 \mathrm{ppm}, \quad 7.24 \mathrm{ppm}, \quad 8.07 \mathrm{ppm}, \quad 7.42 \mathrm{ppm}$, $6.6 \mathrm{ppm}, 15.61 \mathrm{ppm}, 5.85 \mathrm{ppm}$, and $6.81 \mathrm{ppm})$. According to hazardous fact sheet by New Jersey Department of Health dichloromethane can cause skin and eye irritation, sometimes lead to eye damage and breathing its high level can cause nose and throat irritation [25]. Ethyl Acetate, as a solvent used in making of dyes and perfumes [26], was found in blood samples of one thinner handler (was $17.51 \mathrm{ppm}$ ), four paint workers (35.95 ppm, $373.70 \mathrm{ppm}, 25.12 \mathrm{ppm}$, and $38.14 \mathrm{ppm}$ ), and four dry port workers (0.016 ppm, $0.0012 \mathrm{ppm}, 0.01 \mathrm{ppm}$, and $1.06 \mathrm{ppm}$ ). Exposed workers have also reported problems like headache, fatigue, and sometimes weakness during their duty time. This is also supported by previous studies which reported that inhalation of 400 ppm of ethyl acetate for 3-5 min can cause irritation to nose and throat. Its high concentration can lead to headache and also congestion in upper respiratory tract [27]. Ethanol has many applications as a solvent (in manufacturing of paint, ink, varnishes, perfumes), as a fuel, and as raw material for making of chemicals (such as production of ethyl acetate, acetic acid, ethylene, and ethyl acrylate) [28]. It was detected and quantified in only one blood sample of a petrol station attendant ( $8.17 \mathrm{ppm})$, one blood specimen of a textile dyeing worker (1.31 ppm), eight samples of dry port workers (95. 89 ppm, $49.72 \mathrm{ppm}, 141.63 \mathrm{ppm}, 88.80 \mathrm{ppm}, 24.74 \mathrm{ppm}$ $88.80 \mathrm{ppm}, 110.89 \mathrm{ppm}$, and $133.76 \mathrm{ppm})$, and two blood samples of printing press workers (15.61 ppm and $16.7 \mathrm{ppm}$ ). According to hazardous fact sheet prepared by New Jersey Department of Health, exposure to ethanol is moderately irritating to eye and skin. It can cause nose and throat irritation and sometimes shortness of breath. Headache, nausea, vomiting, and unconsciousness are also associated with its exposure [29].

Results of statistical analysis also showed positive relationship between the detected concentrations of different VOCs in blood of workers and their work experience, working hours, and workplace conditions. For example, the phi values $(0.853,0.710,0.514,01.145,0.359$, and 0.389 ) show that there is strong positive relationship between work experience and solvents used in that workplace and indicate that the greater the number of years spent at the workplace, the higher the quantity of solvents in the blood of the respective workers. The case with other parameters is the same (Table 3).

Results of statistical analysis for determining the correlation between the presence of VOCs in blood samples and the diseases reported by the workers working in that environment also depicted strong correlation between these variables. For example, in case of isopropyl alcohol case, phi $=0.359$, which shows a positive relationship between the two variables (isopropyl alcohol and headache). This indicates that the person who is exposed to the workplace conditions having isopropyl and with its concentration detected in blood as bioindicator of this pollutant will be a possible victim of headache. As there is strong positive correlation between the two, the greater the quantity of 
TABLE 3: Correlation between the detected concentrations of different VOCs in blood of workers and their work experience, working hours, and workplace conditions.

\begin{tabular}{lcccccc}
\hline & Isopropyl alcohol & Phenol & Benzene & DCM & Ethanol & Ethyl acetate \\
\hline Work experience & 0.853 & 0.710 & 0.514 & 1.145 & 0.359 & 0.389 \\
Working hour & 0.756 & 0.599 & 0.202 & 0.751 & 0.594 & 0.339 \\
Workplace conditions (status of work) & 0.620 & 0.613 & 0.144 & 0.789 & 0.329 & 0.345 \\
\hline
\end{tabular}

TABLE 4: Correlation between the presence of VOCs in blood samples and the diseases reported by the workers.

\begin{tabular}{|c|c|c|c|c|c|c|}
\hline Diseases reported & Isopropyl alcohol & Phenol & Benzene & DCM & Ethanol & Ethyl acetate \\
\hline Headache & 0.359 & 0.308 & 0.101 & 0.425 & 0.145 & 0.163 \\
\hline Fatigue & 0.260 & 0.311 & 0.082 & 0.403 & 0.269 & 0.132 \\
\hline Skin problems/allergies & 0.403 & 0.377 & 0.124 & 0.541 & 0.265 & 0.200 \\
\hline Irritation to eyes & 0.209 & 0.344 & 0.066 & 0.579 & 0.322 & 0.107 \\
\hline Irritation to nose/breathing problem/nausea & 0.398 & 0.398 & 0.169 & 0.602 & 0.239 & 0.270 \\
\hline Irritation to throat & 0.479 & 0.389 & 0.173 & 0.641 & 0.263 & 0.265 \\
\hline Weakness & 0.478 & 0.385 & 0.171 & 0.530 & 0.242 & 0.293 \\
\hline Dizziness & 0.531 & 0.382 & 0.116 & 0.574 & 0.226 & 0.370 \\
\hline Diabetes & 0.496 & 0.316 & 0.377 & 0.579 & 0.112 & 0.469 \\
\hline Migraine & 0.134 & 0.106 & 0.490 & 0.702 & 0.061 & 0.068 \\
\hline Cancer & 0.066 & 1.000 & 0.021 & 0.087 & 0.030 & 0.033 \\
\hline Obesity & 0.556 & 0.353 & 0.204 & 0.559 & 0.230 & 0.348 \\
\hline
\end{tabular}

isopropyl alcohol in blood, the greater the chance of headache problem among victims (Table 4).

\section{Conclusion}

Workers' safety and surveillance setup is an important subject worldwide. However, in developing countries like Pakistan, it is most neglected one, as workers' safety has never been given a major priority. There are thousands of workers who are routinely exposed to many solvents and chemicals at their workplaces. The present study was thus conducted to quantify working conditions of exposed workers at their workplaces, the major health issues faced by these workers, and the correlation between these two parameters. The efforts made towards this study will be very fruitful in future in light of its outcomes, and it may be very helpful to minimize major health risks in order to ensure complete safety of workers at their workplaces. Different VOCs were detected in above 70 blood samples of the workers belonging to different professions out of a total of 80 samples. Statistical analysis showed a strong relationship between the reported work experience, working hours, and diseases and the detected concentrations of respective volatile organic compounds. Selective and sensitive method of GC-FID was used for the analysis.

\section{Data Availability}

All related data provided in this article are included in the article, and spectrum and charts may be obtained from the corresponding author on request at ghazala_yaqub@ yahoo.com.

\section{Conflicts of Interest}

The authors declare that they have no conflicts of interest.

\section{Acknowledgments}

The authors would like to thank Higher Education Commission, Pakistan, for funding and Ms. Adila Kokab for assistance during statistical analysis.

\section{References}

[1] P. Wilford, VOC Detection and Measurement Techniques, AWE International, San Diego, CA, USA, 2006.

[2] R. J. Delfino, H. Gong, W. S. Linn, Y. Hu, and E. D. Pellizzari, "Respiratory symptoms and peak expiratory flow in children with asthma in relation to volatile organic compounds in exhaled breath and ambient air," Journal of Exposure Science \& Environmental Epidemiology, vol. 13, no. 5, pp. 348-363, 2003.

[3] C. Cai, F. Geng, X. Tie, Q. Yu, and J. An, "Characteristics and source apportionment of VOCs measured in Shanghai, China," Atmospheric Environment, vol. 44, no. 38, pp. 5005$5014,2010$.

[4] H. K. Wilson, "Breath analysis. Physiological basis and sampling techniques," Scandinavian Journal of Work, Environment \& Health, vol. 12, no. 3, pp. 174-192, 1986.

[5] M. Vitali, F. Ensabella, D. Stella, and M. Guidotti, "Exposure to organic solvents among handicraft car painters: a pilot study in Italy," Industrial Health, vol. 44, no. 2, pp. 310-317, 2006.

[6] F.-K. Chang, M.-L. Chen, S.-F. Cheng, T.-S. Shih, and I.-F. Mao, "Evaluation of dermal absorption and protective effectiveness of respirators for xylene in spray painters," International Archives of Occupational \& Environmental Health, vol. 81, no. 2, pp. 145-150, 2007.

[7] K. Demeestere, J. Dewulf, B. De Witte, and H. Van Langenhove, "Sample preparation for the analysis of volatile organic compounds in air and water matrices," Journal of Chromatography A, vol. 1153, no. 1-2, pp. 130-144, 2007.

[8] A. Talapatra and A. Srivastava, "Ambient air non-methane volatile organic compound (NMVOC) study initiatives in 
India-A review," Journal of Environmental Protection, vol. 2, no. 1, pp. 21-36, 2011.

[9] L. H. Van, Volatile Organic Compounds (VOCs). Environmental Chemistry Course Notes, University of Ghent, Ghent, Belgium, 2010.

[10] Hazardous Substances Data Bank (HSDB), Benzene, National Library of Medicine, Bethesda, MD, USA, 2007.

[11] T. K. Alkalde, M. d. C. R. Peralba, C. A. Zini, and E. B. Caramão, "Quantitative analysis of benzene, toluene and xylenes in urine by means of headspace solid phase microexraction," Journal of Chromatography A, vol. 1027, no. 1-2, pp. 37-40, 2004.

[12] P. C. F. D. L Gomes, E. D. D. Andrea, C. B. Mendes, and M. E. P. B. siqueira, "Determination of benzene, toluene and $\mathrm{N}$-hexane in urine and blood by headspace solid-hase microextraction/gas-chromatograpy for the biomonitoring of occupational exposure," Journal of the Brazilian Chemical Society, vol. 21, no. 1, pp. 119-126, 2010.

[13] WHO, International Ethical Guidelines for Biomedical Research Involving Human Subjects Prepared by the Council for International Organizations of Medical Sciences (CIOMS) in Collaboration with the World Health Organization, (WHO), Geneva, Switzerland, 2002.

[14] F. L. Cardinali, J. M. McCraw, D. L. Ashley, M. Bonin, and J. Wooten, "Treatment of Vacutainers for use in the analysis of volatile organic compounds in human blood at the low partsper-trillion level," Journal of Chromatographic Science, vol. 33, no. 10, pp. 557-560, 1995.

[15] D. L. Ashley, M. A. Bonin, F. L. Cardinali et al., "Determining volatile organic compounds in human blood from a large sample population by using purge and trap gas chromatography/mass spectrometry," Analytical Chemistry, vol. 64, no. 9, pp. 1021-1029, 1992.

[16] B. M. El-Haj, A. M. Al-Amri, M. H. Hassan, R. K. Bin-Khadm, and A. A. Al-Hadi, "A GC-MS method for the detection of toluene and ethylbenzene in volatile substance Abuse," Journal of Analytical Toxicology, vol. 24, no. 6, pp. 390-394, 2000.

[17] S. A. Fatima, A. Hamid, G. Yaqub, A. Javed, and H. Akram, "Detection of volatile organic compounds in blood of farmers and their general health and safety profile," Nature Environment and Pollution Technology, vol. 17, pp. 657-660, 2018.

[18] K. Rome and A. McIntyre, "Intelligent use of relative response factors in gas chromatography-flame ionization detection," Chromatography Today, pp. 52-57, Elsevier, Amsterdam, Netherlands, 2012.

[19] ICH Q2 R1, Validation of Analytical Procedures: Text and Methodology, ICH, Geneva, Switzerland, 1995.

[20] F. Tomei, P. Giuntoli, M. Biagi, T. P. Baccolo, E. Tomao, and M. V. Rosati, "Liver damage among shoe repairers," American Journal of Industrial Medicine, vol. 36, no. 5, pp. 541-547, 1999.

[21] New Jersey Department of Health, "Hazardous substance fact sheet-isopropyl alcohol," 2011, http://nj.gov/health/eoh/ rtkweb/documents/fs/1076.pdf.

[22] New Jersey Department of Health, "Hazardous substance fact sheet-phenol," 2010, http://nj.gov/health/eoh/rtkweb/ document/fs/1487.pdf.

[23] Agency for Toxic Substances and Disease Registry (ATSDR), Toxicological Profile for Benzene, U.S. Department of Health and Human Services. Public Health Service, Washington, DC, USA, 2007.
[24] International Programme on Chemical Safety (IPCS), Environmental Health Criteria 150-Benzene, World Health Organization, Geneva, Switzerland, 1993.

[25] New Jersey Department of Health and Senior Services, "Hazardous substance fact sheet-methylene chloride," 2008, http://nj.gov/health/eoh/rtkweb/documents/fs/1255.pdf.

[26] New Jersey Department of Health and Senior Services, "Hazardous substance fact sheet-ethyl acetate," 2002, http:// nj.gov/health/eoh/rtkweb/documents/fs/0841.pdf.

[27] Royal Society of Chemistry, Chemical Safety Data Sheets, Vol. 1, Royal Society of Chemistry, London, UK, 1992.

[28] ANSES-French Agency for Food, Environmental and Occupational Health \& Safety, "Assessing the risks of ethanol," 2013, https://www.anses.fr/en/content/assessing-risksethanol.

[29] New Jersey Department of Health, "Hazardous substance fact sheet-ethanol," 2011, http://nj.gov/health/eoh/rtkweb/ documents/fs/0844.pdf. 